\title{
Community outreach with families of children 0 to 5 years of age: Perceived practices and impacts in Eastern Townships, Quebec, Canada
}

\section{Mathieu Roy ( $\sim$ mathieu.roy7@usherbrooke.ca )}

Centre integre universitaire de sante et de services sociaux de l'Estrie Centre hospitalier universitaire de Sherbrooke du Quebec https://orcid.org/0000-0001-6405-6765

\section{Étienne Lavoie-Trudeau}

Universite de Sherbrooke

\section{Marie-Andrée Roy}

Centre integre universitaire de sante et de services sociaux de l'Estrie Centre hospitalier universitaire de Sherbrooke du Quebec

\section{Irma Clapperton}

Centre integre universitaire de sante et de services sociaux de l'Estrie Centre hospitalier universitaire de Sherbrooke du Quebec

\section{Yves Couturier}

Universite de Sherbrooke

Julie Lane

Universite de Sherbrooke

\section{Linda Bibeau}

Avenir d'enfants

\section{Myrthô Ouellette}

Centre integre universitaire de sante et de services sociaux de l'Estrie Centre hospitalier universitaire de Sherbrooke du Quebec

\section{Chantal Camden}

Universite de Sherbrooke Faculte de medecine et des sciences de la sante

\section{Research article}

Keywords: Community outreach workers; Proximity approaches; Social intervention; Health promotion; Community

Posted Date: August 6th, 2020

DOI: https://doi.org/10.21203/rs.3.rs-42097/v1 
License: (c) (i) This work is licensed under a Creative Commons Attribution 4.0 International License. Read Full License 


\section{Abstract}

Backgound: Community outreach workers support individuals accessing healthcare and other services useful to respond to their needs. Even though community outreach workers have been working in the province of Quebec (Canada) for the past 40 years, their practice is poorly documented (especially for families having children aged 0 to 5 years).

Methods: To document community outreach practice and its perceived impacts for children and families, a content analysis was performed on 55 scientific and grey literature documents, 24 individual interviews, and 3 focus groups including parents, community outreach workers, healthcare employees, and intersectoral partners.

Results: Three main themes were highlighted: 1) characteristics of the population served, 2) concrete actions performed by community outreach workers, and 3) perceived impacts of community outreach on families and children. Community outreach workers were perceived to be essential for reaching out families with vulnerable circumstances and children with special needs. With respect to actions, community outreach workers were reported to tailor their interventions to respond in different but complementary ways to the healthcare system. Perceived impacts included increased access for children and families to services, decreased social isolation, increased parental abilities, increased social capital of families, and confidence towards the healthcare system.

Conclusions: Results also showed that community outreach workers helped to reduce social inequalities in health. This social practice helped to augment the capacity of the healthcare system to fulfill its legal mandate to protect citizen and increase health and well-being. It is crucial that community outreach practices and proximity approaches be encouraged and sustained.

\section{Background}

Although community outreach work is recognized as an effective practice to provide services to hard-toreach individuals (Andersson, 2013), its implementation with families of children aged 0 to 5 is recent (Denis, 2017). In the province of Quebec (Canada), many local partners fostering early childhood health and development have implemented outreach work with families through community outreach workers. It is the most common form of social intervention at the local level to reach families in vulnerable contexts, providing care in their living environment, and promoting the overall development of children (Denis, 2017). Families considered to be in vulnerable situations are those who have limited economic capabilities, who are unable to change their economic, psychosocial, and cultural conditions, and who lack safety and power (Castel, 2000; Spiers, 2005). Families in these vulnerable circumstances are more at risk of disengaging from existing structures and, consequently, traditional health care services may find it harder to reach them (Castel, 2000). Professionals working as community outreach workers act like a relay between the street (i.e. the community) and the resources (e.g. healthcare services; Andersson, 2013). Community outreach work has been recognized as a successful way to connect and support 
different groups of individuals in vulnerable contexts (Santis, Hidalgo, Jaramillo, Hayden, Armijo \& Lasagna, 2013). Families supported by community outreach workers reported higher self-esteem and less depression than those without support (Navaie-Waliser, Martin, Tessaro, Campbell \& Cross, 2000).

Community outreach work is complex, with a focus more on the quality rather than the quantity of the interventions provided (Cofie \& al., 2014). The role of the community outreach worker is dependent on the professional fulfilling the role but also on the needs and context of the individuals they serve (Cofie \& al., 2014; Gunter \& Maccorquodale, 1974). For children and families, community outreach workers aim to create a space of trust, and a close relationship with the individuals they work with. They share information according to needs, and often accompany families to appropriate services to prevent unwanted situations, and to promote health and well-being (Kimbrough-Melton, \& Campbell, 2008). Their role is often all-encompassing and can include everything from helping to integrate immigrant families to preventing the maltreatment of children (McLeigh, Katz, Davidson-Arad, \& Ben-Arieh, 2017; Vostanis, 2016). The community outreach workers link with families, propose activities to foster social support networks, and provide direct support. The outreach worker also plays an important role in supporting collaboration between organizations and families. The need for collaboration is crucial and the use of outreach workers as a way to foster collaboration has been identified (Primomo, Johnston, DiBiase, Nodolf, \& Noren, 2006). This collaborative work requires constant adjustments by the community outreach worker, a good knowledge of the reality of the families (and/or the individuals served), a flexibility in their outreach practices and flexibility of the inter-sectoral partners (Cortis, Katz, \& Patulny, 2009; Kimbrough-Melton, \& Campbell, 2008). Although community outreach work can be offered to everyone, children of families in vulnerable situations are overrepresented in their caseload (Pinto, Manson, Pauly, Thanos, Parks, \& Cox, 2012; Frieden, 2010; Walker et al., 2011; Yoshikawa, Aber, \& Beardslee, 2012).

While the core principles of community outreach work are known, there is much less information on the actual practices of such professionals, and on the conditions needed for their interventions to be successful. We were part of a unique local initiative in the Eastern Townships of Quebec (Canada), where community outreach work had been implemented specifically with families in vulnerable situations for many years. Regional decision-makers were seeking evidence-based data about perceived practices and impacts to help inform decisions about the future of this community approach, particularly in connection with the larger healthcare system.

The main objective of this research was to document the impacts of community outreach work for children and families in vulnerable circumstances in the Eastern Townships, Quebec (Canada). Codeveloped with an advisory committee, specific research objectives were to: 1) describe community outreach workers' practices, and 2) document the perceived impacts of such practice on the overall development of children aged 0 to 5 years and families from vulnerable circumstances.

\section{Methods}




\section{Setting}

The Eastern Townships are located in the southeastern part of the province of Quebec (Canada). This administrative region is one out of 18 health areas in Quebec and includes a mix of urban, semi-urban, and rural areas. The population of this area is approximately 500,000 people (Statistics Canada, 2016). The city of Sherbrooke (Quebec's 6th largest city) is the central city of this area with 170,000 people and is predominantly French-speaking (93.4\%; Statistics Canada, 2016).

\section{Study design}

We used an exploratory, qualitative design (Trudel, Simard, \& Vonarx, 2006), gathering and analysing three sources of qualitative data: 1$)$ scientific and grey literature ( $n=55$ documents; e.g. community journals, activity reports, reference frameworks), 2 ) individual interviews ( $n=24)$, and 3 ) focus groups ( $n$ $=3$ ). We received ethics approval from the CIUSSS Estrie-CHUS and were supported by an advisory committee with whom we co-developed the research proposal and questionnaires. This committee also provided guidance during the study, and helped interpret the results. Committee members included researchers, public health representatives, community outreach workers, and parents.

\section{Participant recruitment process}

Four groups of participants were recruited: 1) community outreach workers, 2) parents receiving outreach support, 3) healthcare employees, and 4) inter-sectoral partners (e.g. community organizations, early childhood centres, and municipal services collaborating with outreach workers). Recruitment was opportunistic and based on a snowball sampling method. Recruitment efforts were made to ensure the greatest variability of participants, especially families (i.e. family composition, single parents, parents from immigrant families as well as English speakers, and families from rural, semi-rural and urban areas).

\section{Data collection process}

Documents were collected from December 2018 to April 2019 from partners, and through emails to community outreach workers. Interviews were conducted from April to June 2019, with focus groups occurring in June 2019. Individual interviews lasted up to 1.25 hours and focus group lasted approximately 1.5 hours. The semi-structured interview grid and focus group guide was developed by the research team for the purpose of this study (see Supplementary file) and was validated by the advisory committee. It covered: 1) description of practices, 2) perceived impacts of the community outreach work for families and children, and 3) any outreach work barriers and/or facilitators. Questions were based on available grey literature available and experiential knowledge of the advisory committee.

\section{Data analysis}

All data (i.e. document analysis, interviews, focus groups) were analyzed with a four-step content analysis procedure (Krippendorff, 2003) performed by a research assistant with a social work background. The 1 st step was a double listening (or reading) of the qualitative material. The 2 nd step 
was a data coding procedure organized in 'axial' and 'selective' stages. The axial stage categorized the data whereas the selective stage organized the categories. The 3rd step was data treatment, which included a semantic analysis. The 4 th and final step was data interpretation. Consultation with the research team, including partners, occurred at all steps to ensure validity in the analysis and interpretation process.

\section{Results}

\section{Participant characteristics}

Table 1 describes how participants (i.e. community outreach workers, parents, healthcare employees, and inter-sectoral partners) were involved in the different data collection strategies.

Table 1

Number of stakeholders participating in interviews and focus groups

\begin{tabular}{|lllllll|}
\hline Data source & \multicolumn{2}{l}{ Stakeholder participants } & & & Total \\
Number
\end{tabular}

\section{Characteristics of the population served}

Regarding the characteristics of the individuals served, three sub-themes were described: 1) family characteristics, needs and dynamics, 3) children's characteristics and needs, and 3) relationships with services.

\section{Themes and subthemes}

Three main themes were identified from the content analysis which included: 1) characteristics of the population served, 2) actions of the community outreach workers, and 3) perceived impacts of the community outreach work on families and children). All these main themes were discussed in the three data sources (Table 2).

Table 2.

Themes and subthemes 


\begin{tabular}{|c|c|c|c|c|}
\hline Themes & Sub-themes & Document & Interviews & Focus \\
\hline $\begin{array}{l}\text { 1) Characteristics of the population } \\
\text { served }\end{array}$ & $\begin{array}{l}\text { 1.1) Family characteristics, } \\
\text { needs and dynamics } \\
\text { 1.2) Children's } \\
\text { characteristics and needs } \\
\begin{array}{l}\text { 1.3) Relationships with } \\
\text { services }\end{array}\end{array}$ & $\begin{array}{l}\mathrm{X} \\
\mathrm{X} \\
-\end{array}$ & $\begin{array}{l}\mathrm{X} \\
\mathrm{X} \\
\mathrm{X}\end{array}$ & $\begin{array}{l}\mathrm{X} \\
\mathrm{X} \\
\mathrm{X}\end{array}$ \\
\hline $\begin{array}{l}\text { 2) Actions of the community outreach } \\
\text { worker }\end{array}$ & $\begin{array}{l}\text { 2.1) Overall approach } \\
\text { 2.2) Tasks and strategies to } \\
\text { reach families } \\
\text { 2.3) Specificities of the } \\
\text { practice }\end{array}$ & $\begin{array}{l}\mathrm{X} \\
\mathrm{X} \\
-\end{array}$ & $\begin{array}{l}\mathrm{X} \\
\mathrm{X} \\
\mathrm{X}\end{array}$ & $\begin{array}{l}\mathrm{X} \\
\mathrm{X} \\
\mathrm{X}\end{array}$ \\
\hline $\begin{array}{l}\text { 3) Perceived impacts of community } \\
\text { outreach on parents and children }\end{array}$ & $\begin{array}{l}\text { 3.1) Increasing social capital } \\
\text { 3.2) Increasing family } \\
\text { empowerment } \\
\text { 3.3) Increasing access to } \\
\text { services }\end{array}$ & $\begin{array}{l}\mathrm{X} \\
\mathrm{X} \\
\mathrm{X}\end{array}$ & $\begin{array}{l}\mathrm{X} \\
\mathrm{X} \\
\mathrm{X}\end{array}$ & $\begin{array}{l}- \\
- \\
-\end{array}$ \\
\hline
\end{tabular}

\section{Characteristics of the population served}

Regarding the characteristics of the individuals served, three sub-themes were described: 1) family characteristics, needs and dynamics, 3) children's characteristics and needs, and 3) relationships with services.

\section{Family characteristics, needs and dynamics}

Families served by community outreach work were described as those living in vulnerable contexts with many socio-economic needs. Families who spoke English at home, who were from multi-ethnic backgrounds, single parent homes, families living in rural areas, and those with low incomes were perceived to living in vulnerable contexts and who community outreach workers hoped to reach. Low 
family incomes were perceived to be associated with families living with generational poverty, parents who were students themselves and/or who received low salaries, or those living with situational poverty caused by a trigger (e.g. accident, lost employment). Family dynamics were reported to be complex, with parents perceived to be physically present but sometimes struggling to be emotionally present, meaning they might not be aware or overlook their child/children's needs. Parents felt that community outreach worker help was important for getting organized to attend multiple appointments. Parents reported needing help to understand their kids, and to feel reassured and protected. Examples of needs discussed by parents included planning school entry or accessing kindergarten, being more organized on a day-today basis understanding their child's physical and/or psychological diagnosis(es) and responding properly to their needs. Beyond concrete help, families reported that having the involvement of outreach workers helped to reduce their isolation, improve relationships, give them time to breathe and release emotional stress. Families described themselves as being resilient in the face of adversity, being resourceful and creative, proud of their families, and down to earth.

Another key characteristic of the families was that they faced persistent, interrelated challenges at different levels. Many parents faced physical and psychological health problems, lack of social and parental abilities, difficulties reading, writing and communicating. Some families had violent couple relationships and experienced conflict in relationships with others in their neighbourhood. Many also suffered social isolation. Regarding occupation, some parents worked, while others didn't, but most had limited employment opportunities. Some were reported to be involved in criminal activities and prostitution. At the financial and material levels, some of them were on the welfare program. Issues with managing money and setting priorities were discussed, and families were reported to frequently search for an apartment or furniture, but often have their electricity services stopped due to limited resources. These families often did not have enough resources to cope with stressors, including poor family member support, living at long distances from organizations making it difficult to reach them. Also, they were not aware of the resources around them and/or mistrusted those resources.

There's a lot of isolation, that is voluntary or not, but it's very present. [...] There's not a lot of resources you know, so we stay isolated, in the known. In this way, nobody [community partners] will come to say that we do our parental job wrongly. (Parent)

\section{Children's characteristics and needs}

Many children were reported to have physical and psychological health problems (e.g. autism, attention difficulties, anxiety, language problems). Community outreach workers and inter-sectoral partners perceived that their basic needs were neglected with children lacking food, clothing or proper hygiene. They also perceived that these needs could bring more sickness, with the need for more medication. Many children were isolated, and were reported to have poor interactions with their parents. Frequently, the home environment lacked rules and structure, which created challenges when entering preschool/school. Children often had to assume adult roles, such as taking care of their parents or supporting them. Children spent more time playing free games than organized games, with poor sleep 
habits, and some falling asleep in front of the television late at night. There were additional developmental challenges such as lack of emotional care and stimulation, the presence of academic difficulties and challenges at preschool. Taken together, these difficulties appeared to suggest that children from these families would begin life with more disadvantages than other children. Despite these, children had many strengths and were described as being autonomous, and having good motor skill development, perhaps related to the fact that they often play outside and protected their siblings.

We [the health care partner and the community outreach worker] work with children with a lot of developmental problems, it's constantly seen. It's children that are under stimulated, with a gap. Often, they have language problems. (Healthcare partner)

\section{Relationships with services}

A lack of awareness about resources and services was reported among families. Even when families knew about these resources or lived with close access to healthcare settings, they might not seek assistance because of a fear of losing their children to the youth protection authorities.

The community outreach worker is less menacing than us [healthcare partners], because she doesn't have the youth protection hat as we do. For her, people see that she works in a___ [basic office right in the community], and don't know how much she is paid for this job. For us, we are menacing, because we don't have choice to report families to youth protection in certain cases. When there are more reports to youth protection, less families come to our services, because it's a little world, everybody knows each other. Sometimes, it's not even us who reported, but some stay mistrustful after that. In this context, it's very less menacing when the community outreach worker does the approaches with them. (Healthcare partner)

As a result of this fear, parents may not enrol children in kindergarten, thereby increasing further their family and child's isolation. Some families struggle with rigid processes to access resources or services, may not understand those processes, and may have difficulties completing paperwork due to poor reading and writing abilities and the French language, all of which can provoke misunderstanding and family. Families are aware of long wait lists to access services. When their children live with difficulties without knowing the diagnosis, they report losing faith in the healthcare system knowing that they may wait months or years to see a specialist. The rigidity of the healthcare system can be a challenge for them. When they miss appointments, they may be discharged. They are required to set needs and goals but may not be able to identify them, often after a limited number of appointments, provoking frustration and a feeling of wasted time for both families and professionals.

\section{Actions Of The Community Outreach Workers}

Three subthemes were described for the actions of the community outreach workers including: 1) overall approach, 2) tasks and strategies to reach families, and 3) specificities of practice.

\section{Overall approach}


The overall approach to community outreach followed the philosophy underpinning the proximity approach. This included principles such as being grounded in families' reality and context, being flexible, strengths-based, and informal, creating a strong trust relationship, and fostering engagement and participation of families. Compared with other approaches, providing education or information to a family was perceived to be secondary to being present in the moment and respecting the rhythm of the family and their capabilities. This approach was reported to allow children and parents to celebrate successes, experience pleasure and emotion, and is designed to reduce family fragility. This approach is designed to help families to identify their own needs and then to support them and even accompany them as they access needed services. Other characteristics of the proximity approach reported include helping families to have a better understanding of their situation, helping them to trust healthcare and other services and to stay involved and engaged when they are waiting for healthcare services.

By using the proximity approach, we try by every manner to be available and have a familiar presence. It's not only about giving information. People don't care about information. They want to have a familiar presence, a welcoming face. They don't know about our functions, they don't care. By deploying community outreach workers and using the proximity approach in the community, we create trust links, and we are anchored in the community. (Community Organization Partner)

Community outreach workers' tasks were perceived to address several important aspects. They were reported to provide direct support to families, by accompanying families to the organizations and helping translate professional language into lay language, being presence in difficult moments, and advocating for parents.

They need to be accompanied because they are in a disorganisation period. They can't do it alone and it's complex to analyse the situation. In vulnerable environment, people don't have a lot of education. Also, the system, like welfare, hospital, etc., works with forms. It's a barrier that contribute to reduce their understanding of the situation. Sometimes, they go to an appointment alone, and they say that it went well, but they don't even know why. (Community outreach worker)

They also helped to reduce barriers, link families with other parents and the community and introduce new families, and provide knowledge and practice information about fostering child development. Community outreach workers connect with other partners, work collaboratively, create confidence in, and promote their role with other organizations. Also, outreach workers improve their own practice and their profession by finding new strategies to connect families, and by documenting and developing a culture of regular evaluation, sharing their knowledge of barriers to access services, and the lack of services with all partner organizations to help them adapt the services they offer.

\section{Tasks and strategies to reach families}

Different strategies were used by the community outreach workers to connect with families. Those strategies could be: 1) active or passive (going to the street to meet people or letting people come to them), 2) traditional or imaginative/roundabout (introduce themselves directly to offer a ride and talk 
during this time), and could 3) involve the outreach worker only, or other people (pivotal person, other families). Primary strategies included public strategies, such as appearing on community television or placing posters in targeted areas where families typically frequent, including grocery stores and health partners' offices. Workers provided families with transportation, as a pretext to talk with them and create a relationship. They were active on social networks, including those of their own profession, those of other partners, local Facebook pages and Facebook Messenger application. The most used and recognized strategy was visiting places where families were. Community outreach workers try to connect with families in this way to show that they are an integral part of the settings where families gather, and to increase confidence in their work and reduce fear towards them.

All the pretexts are good. The idea is to create a first contact. [...] The more you are seen, the more you are part of the picture. The person will come talk to you like you know each other, even if you don't really. (Community outreach worker).

\section{Specificities of practice}

Specificity in community outreach work was related to the posture, or stance, taken by the outreach worker. They are closer to families than conventional workers, providing opportunities to intervene or discuss with family issues that might be sensitive or difficult for them. Also, they act as mediators between families and the healthcare system or other services, filling in the gap left by differences in language and/or culture. They can act as a guide to help service partners recognize the barriers related to service access, the lack of services, and how those partners might improve their services. Outreach workers can be available to a family almost instantly, and are able to build relationships slowly with families over months and years. They are also able to help obtain services for a family, and be with the family while they are waiting to keep them involved and engaged. They contact families in a number of ways, including use of texts and social networks, which is not possible for some organizations. Also, it was noted that perceived areas of weakness of the healthcare structure for these families were actually the strengths of outreach practice, including humanity and availability, and that families didn't need to have a specific issue to consult workers.

I see her like a help, a support, somebody who listen to me. It's all that a friend could do, but with more resources, more directions to give. (Parent)

\section{Perceived impacts of community outreach work on families and children}

Perceived impacts of the community outreach work on families and children included: 1) increasing social capital, 2) increasing family empowerment, and 3) increasing access to services.

\section{Increasing social capital}

With the help of the community outreach worker, parents reported being less isolated and socialized more with their children and community. The same observation was made for the children, who tended to socialize more. Community outreach workers proposed different types of social activities to families and 
were present with parents during difficult times. Outreach workers helped parents to help their children, and developed stable, significant relationships with them.

It goes a lot with activities. [...] In every activity, like collective cooking, coffee meeting, it's really interesting to go search the families, to get people to know you. For example, for moms who stay at home with their kids, and being anti-kindergarten, if they are going in collective cooking, and that children play together, it's a good debut. It can work the child socialization, decrease the isolation and see other way to do things It's a bit the same for the parents. (Healthcare partner)

\section{Increasing family empowerment}

Increasing families' empowerment was related to increasing parents' feelings of self-efficiency, overall self-esteem, and their parenting abilities, but specifically to helping parents develop positive parenting practices. Parents became more responsible about their children's needs, skills, and development. They adopted more healthy behaviors, were more available for their children, and tend to be more socially active. All of the above contributed to fostering child development and well-being, by increasing their autonomy, ability to express emotions, and communication skills.

There is a big change. She is saying that I learned to her how to clean her house to protect her kids. How she is now capable to organize her time. It responds at her kids needs by her actions. (Parent, with the help of translator)

\section{Increasing access to services}

Community outreach workers helped to increase families' confidence towards accessing community social and healthcare services which encouraged them to seek support services. They were able to create trust between themselves and the families, something that can be more difficult to establish with the traditional healthcare system and the school system. Many participants mentioned how important it was to put names to faces, to humanize services, and to understand the function and the pathways of the health care services. These actions helped prepare families to access community health and social services. Many participants believed that this helped to improve the continuum of care and ensure children received the services they needed.

[families think this way, according to this Comm. Outreach Worker] I want to go, but I don't know how. I don't want to go alone. There's mistrust. The health care system is frightful. It's hospital, not home. The health care system doesn't make any sense for them, it's too big. But, if I present you [name of a psychosocial counsellor], if he goes with you, it might make sense to go there. (Community outreach worker).

\section{Discussion}

This study aimed to describe: 1) community outreach workers' practices, and 2) document the impacts of such practice on the overall development of children and needs of families living in vulnerable contexts. 
Results were consistent between all data sources. Our results show that community outreach workers can effectively reach families and children with social challenges and needs, as previously reported in the literature (Navaie-Waliser, Martin, Tessaro, Campbell \& Cross, 2000; Santis, Hidalgo, Jaramillo, Hayden, Armijo \& Lasagna, 2013). Outreach workers establish trusting relationships with parents, helping families to identify their needs and providing them with a social safety net. Their interventions have indirect impacts on the children, through worker support of the parents. Results showed that through parental empowerment, and increased social capital and access to services, parents become better able to take care of their children and more confident to do so. Community outreach workers actions also have a direct impact on families, by reducing isolation between their children and the community. Through these direct and indirect activities parents are able to enhance their supportive social circle. By virtue of their role in the community, outreach workers work in an environment that has several advantages over the traditional healthcare system. They are able to establish a relationship between individuals and the different organizations providing services in the community because they work within a context with flexibility, flexibility that is not always present for workers in healthcare organizations. Flexibility seems to be a key factor in developing relationships with families in vulnerable contexts (Kimbrough-Melton, \& Campbell, 2008). Where environments are not as flexible, it can be more difficult to emphasize trust and relationship-building. A community outreach worker has the flexibility and time to work on a relationship for months even when families have not identified their own needs, because their primary goal at the outset is to build trust. This trust and relationship-building are examples of the community outreach worker's role to focus on quality over quantity (Sofie \& al., 2014). Outreach work allows families to have a close and personalized access to healthcare services, with a rapid response, more flexible rules of intervention, as well as roles and ways to communicate with parents. Community workers take into account language, culture, values, habits, rhythm, and capabilities of families with regard to accessing services. These aspects of the outreach role appear to make a difference between acceptance or rejection of services. In situations where the healthcare system is not able to adapt enough to allow individuals who do not meet admission criteria to get access to services, the role of the community outreach worker is even more important.

By creating a trusting relationship and being flexible with families, children and their parents are better supported which in turn supports healthy child development. This is crucial for children prior to school age and may make the transition to preschool/school an easier one. With a proximity approach guiding the interventions, this may allow workers to more effectively connect with families in vulnerable contexts. It may also help to involve and empower families to work to improve their own quality of life to a greater extent than through the use of healthcare services. In addition, their collaborative work with partners may make it easier to refer families between organizations and outreach workers in both directions. In this way, partners can be informed of families' challenges and needs and work to find solutions because community outreach workers function to increase service access for families with needs. In the end, community outreach workers support the healthcare system in fulfilling its responsibilities of accessibility, continuity and quality of services for their respective populations and territories. Outreach 
work may have the potential to reduce healthcare costs when families who are vulnerable and have serious needs are identified early.

\section{Limits}

It may be difficult to generalize our results to other populations or environments, given the local context in which our study was conducted. However, the characteristics of the population and actions of community outreach workers were described so other researchers can assess the applicability of the results to other settings. Social desirability bias might also have influenced our results, especially for families. In addition, the community outreach worked needed to be present for some interviews due to language barrier and/or mistrust of the interviewer, who was representing a healthcare organization. It may have been difficult for parents to be candid, especially when asked about the community outreach worker. During the interviews (not the focus groups), half of the parents spoke only a little and for a shorter period than expected. In this way, their voices might be underrepresented compared to other stakeholders. Finally, it was a challenge at times to determine specific impacts of the outreach work, given the multidimensional interventions of community outreach workers.

\section{Conclusions}

Community outreach workers help to reduce social inequalities in health for families in vulnerable situations. Outreach workers can approach families with challenges, build trust with them, identify their needs, and strengthen the traditional healthcare system which is often unable to reach them. Workers do so by using a proximity approach. Community outreach workers can have both direct and indirect impacts on families and children by increasing social capital, family empowerment and access to services. In collaboration with other health and social service partners, they increase families' access to services, To meet the needs of vulnerable families, community outreach practices should be both encouraged and sustained.

\section{Declarations}

Ethics approval and consent to participate: This study was approved by the Ethics Committee of the CIUSSS de l'Estrie - CHUS (\#2019-3063). All participants provided a written informed consent form

Consent for publication: Not applicable

Availability of data and material: The datasets generated and/or analysed during the current study are not publicly available due to confidentiality of patient data but are available from the corresponding author on reasonable request. The interview grid and the focus group guide are available as a supplementary file.

Competing interests: The authors declare no competing interests 
Funding: This work was co-funded the CIUSSS de l'Estrie - CHUS University Institute of Health and Social Services, by local associations of inter-sectoral partners, by the Collectif estrien $0-5$ years and by Avenir d'enfants. All body funders have had no role in the design of the study, data collection, analysis, interpretation and in writing the manuscript.

Authors' contributions: MR and CD conceived the study with the help of all authors. ELT was responsible for data collection and analysis under the supervision of MR and CD. ELT wrote the first draft of this manuscript. MR and CD correct this draft and share with all co-authors who read and approved the article. All authors have read and approved the manuscript.

Acknowledgements: We are indebted to all community outreach workers, parents and partners who participated in this study.

\section{References}

Andersson, B. (2013). Finding ways to the hard to reach-considerations on the content and concept of outreach work. European Journal of Social Work, 16, 171-186. https://doiorg.ezproxy.usherbrooke.ca/10.1080/13691457.2011.618118

Castel, R. (2000). The Roads to Disaffiliation: Insecure Work and Vulnerable Relationships. International Journal of Urban \& Regional Research, 24, 519. https://doi-org.ezproxy.usherbrooke.ca/10.1111/14682427.00262

Cofie, L.E., Barrington, C., Akaligaung, A., Reid, A., Fried, B., Singh, K., et al. (2014). Integrating community outreach into a quality improvement project to promote maternal and child health in Ghana. Global Public Health, 9, 1184-1197. https://doi-org.ezproxy.usherbrooke.ca/10.1080/17441692.2014.952656

Cortis, N., Katz, I., \& Patulny, R. (2009). Engaging hard-to-reach families and children. FaHCSIA occasional paper, 26. http://dx.doi.org/10.2139/ssrn.1728576

Davenport, H. (2012). Clipboards and cups of tea: Two women's narrative constructions of professional identity in sure start outreach work. Early Years: An International Journal of Research and Development, 32, 277-287. https://search-ebscohost-com.ezproxy.usherbrooke.ca/login.aspx? direct=true\&db=eric\&AN=EJ980838\&lang=fr\&site=eds-live

Frieden, T.R. (2010). A framework for public health action: The health impact pyramid. American Journal of Public Health, 100, 590-595. https://doi.org/10.2105/AJPH.2009.185652

Fujiwara, T., \& Chan, M.H. (2009). Role of behavioral outreach worker in increasing mental health service utilization for children. Pediatrics International: Official Journal of The Japan Pediatric Society, 51, 167168. Doi: 10.1111/j.1442-200X.2008.02792.x 
Gunter, B.G., \& Maccorquodale, D.W. (1974). Informal role strategies of outreach workers in family planning clinics. Journal of Health \& Social Behavior, 15, 127-135. DOl: 10.2307/2137192

Kimbrough-Melton, R.J., \& Campbell, D. (2008). Strong Communities for children: a community-wide approach to prevention of child abuse and neglect. Family \& Community Health, 31, 100-112. doi: 10.1097/01.FCH.0000314571.28410.98

Krippendorff, K. (2003). Content analysis: An introduction to its methodology. Thousand Oaks, CA: Sage Publications.

McLeigh, J.D., Katz, C., Davidson-Arad, B., \& Ben-Arieh, A. (2017). The cultural adaptation of a community-based child maltreatment prevention initiative. Family Process, 56, 393-407. https://doi.org/10.1111/famp.12193

Navaie-Waliser, M., Martin, S.L., Tessaro, I., Campbell, M.K., \& Cross, A.W. (2000). Social support and psychological functioning among high-risk mothers: The impact of baby love maternal outreach worker program. Public Health Nursing, 17, 280-291. https://doi-org.ezproxy.usherbrooke.ca/10.1046/j.15251446.2000.00280.x

Pinto, A.D., Manson, H., Pauly, B., Thanos, J., Parks, A., \& Cox, A. (2012). Equity in public health standards: A qualitative document analysis of policies from two Canadian provinces. International Journal for Equity in Health, 11, 28. Doi:10.1186/1475-9276-11-28

Primomo, J., Johnston, S., DiBiase, F., Nodolf, J., \& Noren, L. (2006). Evaluation of a community-based outreach worker program for children with asthma. Public Health Nursing, 23, 234-241. https://doiorg.ezproxy.usherbrooke.ca/10.1111/j.1525-1446.2006.230306.x

Santis, R., Hidalgo, C.G., Jaramillo, A., Hayden, V., Armijo, I., \& Lasagna, A. (2013). A family outreach intervention for engaging young out-of-treatment drug users: Pre- versus post-treatment comparison. Journal of Substance Abuse Treatment, 44, 61-70. https://doi-

org.ezproxy.usherbrooke.ca/10.1016/j.jsat.2012.03.003

Statistics Canada (2016). Census Profile, 2016 Census. Government of Canada.

Spiers, J.A. (2005). A concept analysis of vulnerability. The Essential Concepts of Nursing: Building Blocks for Practice, 331.

Trudel, L., Simard, C., \& Vonarx, N. (2006). Is qualitative research necessary exploratory? Qualitative Researches, 5, 38-55.

Vostanis, P. (2016). New approaches to interventions for refugee children. World Psychiatry, 15, 75-77. https://doi.org/10.1002/wps.20280 
Walker, S.P., Wachs, T.D., Grantham-McGregor, S., Black, M.M., Nelson, C.A., Huffman, S.L., et al. (2011). Inequality in early childhood: Risk and protective factors for early child development. The lancet, 378 , 1325-1338. https://doi.org/10.1016/S0140-6736(11)60555-2

Yoshikawa, H., Aber, J.L., \& Beardslee, W.R. (2012). The effects of poverty on the mental, emotional, and behavioral health of children and youth: implications for prevention. American Psychologist, 67, 272. https://doi.org/10.1037/a0028015

\section{Supplementary Files}

This is a list of supplementary files associated with this preprint. Click to download.

- COREQGrid.docx

- InterviewFocusgroupguide.docx 